\title{
Desiccation risk favours prevalence and diversity of tardigrade communities and influences their trophic structure in alpine ephemeral rock pools
}

\author{
Matteo Vecchi $(\mathbb{D} \cdot$ Claudio Ferrari - \\ Daniel Stec $\mathbb{D} \cdot$ Sara Calhim $\mathbb{D}$
}

Received: 3 June 2021 / Revised: 13 January 2022 / Accepted: 10 February 2022 / Published online: 1 March 2022

(C) The Author(s) 2022

\begin{abstract}
Rock pools are ephemeral freshwater habitats characterized by their small size, well-defined boundaries, and periodic desiccation, making them ideal model systems to answer numerous ecological questions. Although there are numerous studies on rock pool fauna around the world, tardigrades have only rarely been recorded. We conducted the first tardigrade-focused study on rock pools by quantitatively
\end{abstract}

Handling editor: Dani Boix

Supplementary Information The online version contains supplementary material available at https://doi. org/10.1007/s10750-022-04820-0.

M. Vecchi $(\bowtie) \cdot$ S. Calhim

Department of Biological and Environmental Science, University of Jyvaskyla, PO Box 35, 40014 Jyvaskyla, Finland

e-mail: matteo.m.vecchi@jyu.fi;

matteo.vecchi15@gmail.com

\section{Ferrari}

Department of Chemistry, Life Sciences

and Environmental Sustainability, University of Parma,

Parco Area delle Scienze 33/A, 43124 Parma, Italy

\section{Stec}

Institute of Systematics and Evolution of Animals, Polish Academy of Sciences, Sławkowska 17, 31-016 Kraków, Poland

D. Stec

Institute of Zoology and Biomedical Research, Jagiellonian University, Gronostajowa 9, 30-387 Kraków, Poland extracting and classifying them from rock pools in the Italian Apennines. Rock pools were divided into three types, based on maximum duration of their inundation period. Following the patterns usually observed with rock pool invertebrates, we tested the hypothesis that desiccation has a negative effect on prevalence, abundance, and diversity of tardigrades, and thus could alter the trophic structure of their communities. In contrast to what is commonly found for other animal groups in the same type of habitat, we found that tardigrades were more diverse and prevalent in shallower, more desiccation prone, rock pools. Moreover, the trophic structure of tardigrade communities was different among the different pool types. Lastly, we also provide DNA barcodes of the most commonly found taxa. Ultimately, our study demonstrates that tardigrade communities in rock pools provide a valuable model system for the study of abiotic factors influencing meiofauna communities.

Keywords Tardigrada $\cdot$ Rock pools $\cdot$ Desiccation . DNA barcoding $\cdot$ Community ecology $\cdot$ Meiofauna

\section{Introduction}

Rock pools are eroded depressions that occur in a matrix of bedrock that accumulate a layer of unconsolidated bottom sediment by trapping material transported by runoff and wind (Brendonck et al., 2016). These habitats occur all over the globe in all major 
biomes and depend mainly on precipitation for filling (Jocqué et al., 2010). Therefore, they are ephemeral, generally oligotrophic (Jocqué et al., 2010) and experience extreme fluctuations in their abiotic parameters (especially $\mathrm{pH}$, temperature, and dissolved oxygen; De Vries, 1996; Brendonck et al., 2000). Rock pools have been proposed as a model system in ecology and evolutionary studies (Srivastava et al., 2004; Brendonck et al., 2010) as they are small, pristine environments with clear boundaries; thus, they can be subjected to experimental manipulations and generally host a simple community.

About 460 aquatic animal species have been recorded from freshwater rock pools around the world (Jocqué et al., 2010). These animals can be classified as passive or active dispersers. Passive dispersers (for example tardigrades; Ptatscheck et al., 2018; Fontaneto, 2019) disperse mainly in a resting stage via wind and overflow of water between pools, and thus can be rock pool specialists. Active dispersers are those that can actively migrate (usually only during the adult stage) between different pools, have broad distributions and occur in a wide range of temporary habitats in addition to rock pools. The main factors driving animal community composition in rock pools are the size and hydroregime of the rock pool (Jocqué et al., 2007; Vanschoenwinkel et al., 2009), with passive disperser being more influenced by those environmental parameters than active dispersers (Vanschoenwinkel et al., 2009). Different responses of animal groups have been found to respond differently to the hydroregime. For example, diversity and abundance of insects and crustaceans decreased in rock pools with shorter hydroperiods in a Jamaican coastal system (Therriault \& Kolasa, 2001). The opposite pattern was reported for rotifers and tardigrades by Jocqué et al. (2007), who found higher densities in pools with shorter hydroperiods. Developmental constraints, such as development time, can prevent larger organisms and predators from occurring in pools with shorter hydroperiods, which, in turn, allows the proliferation of smaller and less competitive organisms like tardigrades adapted to ephemeral habitats (Tevis, 1966; Jeffries, 1994; Jocqué et al., 2007).

Tardigrada (also known as water bears or moss piglets) is a phylum of micrometazoans of about 50-1200 $\mu \mathrm{m}$ in size (Møbjerg et al., 2018), with more than 1300 species described worldwide (Guidetti \& Bertolani, 2005; Degma \& Guidetti, 2007; Degma et al., 2021). When colonizing terrestrial environments, tardigrades require at least a film of water surrounding their bodies to perform activities necessary for life. However, because of their ability to enter cryptobiosis (a temporary and reversible suspension of metabolism) in all the phases of their life cycle, some species of limnoterrestrial tardigrades can withstand desiccation (anhydrobiosis; Wright, 2001) and freezing (cryobiosis; Guidetti et al., 2011). As a result of their small size and metabolic adaptations, tardigrades can colonize a variety of environments, ranging from limnoterrestrial (leaf litter, soil, mosses, lichens) to aquatic habitats (periphyton, sediment) (Nelson et al., 2018) and with extreme climatic conditions (for example glaciers (Zawierucha et al., 2016) and deserts (Neher et al., 2009)).

Tardigrade records in rock pools are extremely limited, having been recorded only seven times in the scientific literature. Interestingly, although only few studies have recorded their existence, their occurrence has been cited in rock pools throughout the world (Namibia, Koste (1996); Ivory Coast, Snoeks et al. (2021); South Africa, De Vries (1996); Israel, Spencer et al. (1999); Utah, USA, Jocqué et al. (2007); Spain, Velasco-González et al. (2020); Australia, Boix et al. (2016)), emphasizing a potential association between tardigrades and rock pools.

The main aim of this paper is to test if tardigrades in rock pools represent a good model system for the study of the effects of extreme environmental stresses (desiccation) on community composition. Specifically, following the observations of Jocqué et al. (2007) that tardigrades were more abundant in rock pools with shorter hydroperiods, we tested the hypothesis that tardigrade prevalence, abundance and diversity are higher in rock pools that desiccate faster and more often.

\section{Materials and methods}

Study area

The studied rock pools are located inside the "Parco Nazionale dell'Appennino Tosco-Emiliano" (Tuscan-Emilian Apennine National Park), Italy. The area is characterized by a complex geological structure (Mariani et al., 2018). All the main peaks and most of ridge's summits of the Tuscan-Emilian 
district are made of sandstones belonging to the Macigno formation. During the Last Glacial Period (115,000-11,700 years ago), glaciers covered almost all the peaks of the northern Apennines and the moving ice left different geomorphological formations such as sheepback rocks. All the rock pools studied are made of sandstone in sheepback rocks. In the study area, the vegetation of montane belt is characterized by Fagus sylvatica L., 1753 forests (Foggi \& Rossi, 1996) and Vaccinium-heaths for the subalpine belt (Pignatti, 1994; Ferrari \& Piccoli, 1997; Tomaselli et al., 2019). The yearly average temperature recorded from the closest climatic station (Lake Paduli, Massa-Carrara; Lat: 44.35 Lon: 10.14) is $8.2{ }^{\circ} \mathrm{C}(\min -16.0, \max 31.3)$ with 75 days of frost and $2268 \mathrm{~mm}$ of precipitations (SM.01).

Rock pools sampling and characterization

Fifty-six rock pools from 11 clusters were selected for this study. Clusters (Fig. 1a-b, SM.01) are isolated rocky outcrops where pools (from 1 to 19 per cluster) occurred. Cluster locations are shown in Fig. 2. Due to the irregular shape and absence of water during the sampling, the maximum water level (depth) was impossible to measure accurately but was estimated. Pools were divided into three categories based on the approximated maximum depth (Fig. 1c-d, SM.02): "Pans" ( $<2 \mathrm{~cm})$, "Intermediates" $(>2 \mathrm{~cm},<5 \mathrm{~cm})$ and "Holes" $(>5 \mathrm{~cm})$. We used maximum depth to divide the pools in three classes because this gives a reasonable indication of the maximum duration of the inundation period (Jocqué et al., 2006; Vanschoenwinkel et al., 2009; Anusa et al., 2012). Thus, the three categories also represent three different classes of inundation period maximum duration (short for Pans, intermediate for Intermediates and long for Holes). Rainfall and temperature also influence rock pools inundation period (Marcus \& Weeks, 1997), but those environmental factors can be considered almost identical between the analysed pools due to their geographic proximity and similar elevation. Sampling was conducted during April-May 2019 and June 2020 on three occasions, however most of the samples were collected in the last sampling trip (SM.01). Each pool was sampled only once; however, during the multiple sampling visits all the analysed rock pools were completely dry at least once (i.e., none of them hold water permanently). The sediment of each pool was manually homogenized (to avoid
Fig. 1 Photographs of rock pools taken during their dry phase. a Location of pool cluster C; b Location of pool cluster E; c Pool C7 from cluster C; d Pool E11 from cluster E. Photos courtesy of Tommaso Sandri
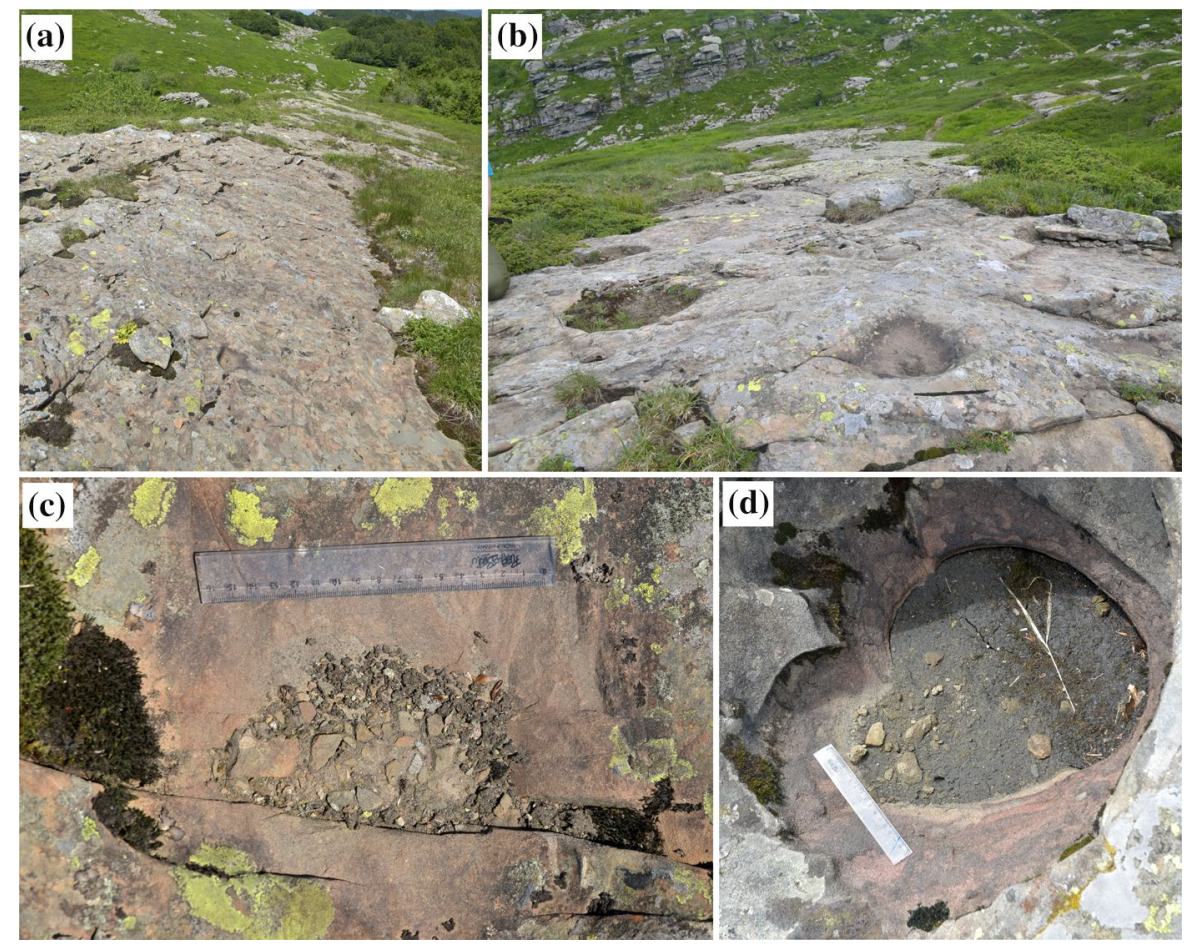
Fig. 2 Locations of the sampled rock pool clusters

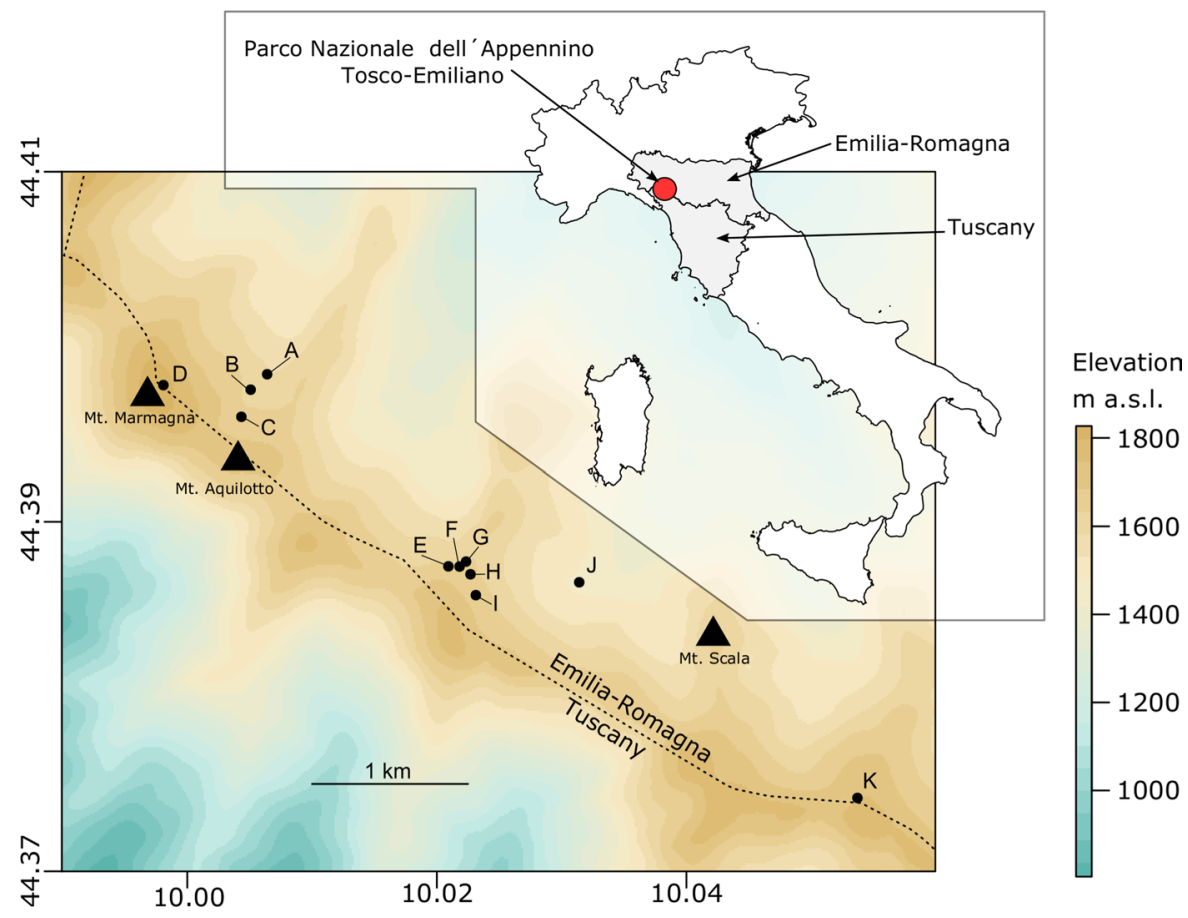

sampling error due to low-scale variability in meiofauna distribution; Gansfort et al., 2018) and scraped with a clean metal spoon. The sediments were collected in clean plastic bags (when wet) or paper bags (when dry). Wet samples were left to dry protected from light at room temperature $\left(20^{\circ} \mathrm{C} \pm 1\right)$, then kept frozen at $-20{ }^{\circ} \mathrm{C}$ until use. One aliquot of rock pool E19, which contained water when sampled, was kept frozen instead of being dried, and was later examined for potential predators of tardigrades.

\section{Tardigrade extraction}

Dry samples were sieved through a $1 \mathrm{~mm}$ screen to remove stones and large organic fragments that could bias the weighing. Aliquots of the sieved dry samples (from 0.05 to $5.39 \mathrm{~g}$, according to the amount of available sample; SM.01) were placed in $50 \mathrm{~mL}$ plastic tubes and left to rehydrate overnight with $10 \mathrm{~mL}$ of distilled water. Then $30 \mathrm{~mL}$ of boiling distilled water was added to each tube to kill and relax all the fauna and avoid live tardigrades griping onto sediment fragments and avoiding extraction. Fauna extraction was performed by centrifugation with Ludox according to Bartels \& Nelson (2006). From selected samples, an additional portion (not counted for the calculation of tardigrade densities) was processed to extract more specimens for DNA sequencing. Samples for DNA sequencing were chosen to maximise the diversity of sequenced taxa by selecting the ones with abundant populations and target groups that are taxonomically challenging and likely comprise cryptic/pseudocryptic species.

\section{Other fauna extraction}

Rotifers, mites and nematodes were consistently extracted as collaterals of tardigrade extraction. These were only semi-quantitatively analysed and classified as Absent, Rare, Common or Abundant (see definitions in SM.01). When occasionally chironomid carcasses were retrieved, they were recorded (SM.01). The frozen aliquot of pool E19 was thawed and qualitatively examined for the presence of potential predators (SM.01).

\section{Microscopy and tardigrade identification}

Specimens for light microscopy were mounted on microscope slides in a small drop of Hoyer's medium and secured with a cover slip, following the protocol by Morek et al. (2016a, b). When more than 80 
tardigrades were extracted from a sample (only in pools C12 and E1), only a subsample of about 80 individuals were mounted on slides (the number was determined based on the maximum number of animals per sample that could be analysed with the available time and resources; a similar approach was used in Bartels \& Nelson, 2006). Slides were examined under a Zeiss Axio Scope A1 light microscope with phase and Nomarski differential interference contrast (PCM and NCM, respectively; named collectively as light contrast microscopy, LCM). Tardigrades were identified to genus level as it was not possible to identify every individual to the level of nominal species. Genera identification was performed following Ramazzotti \& Maucci (1983) and descriptions/redescriptions or recent reviews of the identified genera: Claxton (1998), Pilato (1992), Biserov (1997-98), Bertolani et al. (2014), Morek et al. (2016a, b), Vecchi et al. (2016), Hansen et al. (2017), Stec et al. (2018), Gąsiorek et al. (2019a, b), Gąsiorek \& Michalczyk (2020), Tumanov 2020 and Stec et al. (2021). A quantitative faunistic table of the genera found in each sample is provided in SM.01. Tardigrade genera were divided in two main functional feeding groups according to their ability to feed on other animals and thus the ability to exploit them as resources: Carnivorous (Carnivorous + Omnivorous) and Non-Carnivorous (Herbivorous + Microbivorous). Division into feeding groups was done according to Zawierucha et al. (2019).

\section{Data analysis}

Bayesian Generalized Linear Mixed Models (BGLMM) were used to estimate the unbiased prevalence (defined as the probability of finding at least one tardigrade by analysing one gram of dry substrate, the number of individuals per gram of dry substrate (abundance), the number of taxa (diversity), and the proportion of non-carnivorous individuals. The posterior distributions of the unbiased estimates were then used to test the differences between the three groups using the indices of effect existence (Bayesian $P$ value) and significance-Std. Effect size (e.g.: Cohen's $h$ and Cohen's $d$ ) according to Makowski et al. (2019a) and Cohen (1988). Following Makowski et al. (2019a), in this paper we define the significance of an effect as a combination of $P$ value (existence) and effect size; therefore, we jointly evaluated both those metrics when discussing the results. Note that since covariate terms are only interpreted as having an effect or not, they have marginal relevance to the research question.

This Bayesian approach was chosen over a Frequentist approach due to its ability to better deal with very unequal sample sizes across random effect groups, large variation in the amount of weighted sample, and by offering more freedom in the modelling of the response data distribution (McElreath, 2018). This approach was also chosen over direct testing of the effect of predictors on a response variable (which allows testing of only two differences between three groups) as it allows testing all three comparisons between pool types. Pool surface area was used as covariate in all the analyses. Due to the low amount of material in some samples, it was not possible to recover enough animals to build species accumulation curves and thus obtain an unbiased estimate of genera numbers with respect to the sampling effort (Deng et al., 2015). Instead, we account for potential sampling bias in determining the number of genera by using the number of individuals mounted on slides and taxonomically identified as a second covariate in the diversity analysis. For model estimates, the proportion of non-carnivorous individuals, tardigrade density and rotifer abundance were included as covariates, as both tardigrades and rotifers are known food items of carnivorous tardigrades (Kosztyła et al., 2016; Roszkowska et al., 2016; Bryndová et al., 2020), and thus could influence their proportion. Although the sampling in this study was performed on three different occasions, the sampling period was not considered in the analyses as only a few samples were collected in the first and second sampling events (11/56 and 2/56 respectively; SM.01) and in those two sampling trips only clusters A, C, D, E and $\mathrm{K}$ were sampled. Moreover, annual fluctuations in tardigrade abundances are known to occur mostly in aquatic or hygrophilous species (Schuster et al., 1977; Kathman \& Nelson, 1987; Kinchin, 1996; Schuster \& Greven, 2007). For more xeric species (like those of the genus Ramazzottius) annual population fluctuations have not been observed (Kinchin, 1989, 1996) and despite the analysed pools being defined as freshwater aquatic habitats, their tardigrade fauna is mostly composed of xerophilous taxa (Ramazzotti \& Maucci, 1983). Geographic distance between samples was not included in the model as a random factor due 
to the inaccuracy of GPS measurements that is far higher than the distance between most of the samples (SM.01). Cluster identity was used as a random factor because clusters have different slopes, exposure, and/ or mineral composition that can likely influence the local tardigrade communities, and by having different geographic locations they can also partially account for the spatial distribution. Prevalence and abundance were estimated in the same model, whereas diversity was estimated in a separate one. Analysis workflow and R script are presented in SM.03. Analyses were performed with "R v. 4.0.2" software (R Core Team, 2020) and associated packages "bayestestR v. 0.3.0" (Makowski et al., 2019b), "patchwork v. 1.1.0" (Pedersen, 2020), "R2Jags v. 0.6.1" (Su \& Yajima, 2015), "tidyverse v. 1.3.0" (Wickham et al., 2019) and "vegan v. 2.5.6" (Oksanen et al., 2020); BGLMMs were fitted with "JAGS v. 4.1.0" (Plummer, 2003).

DNA sequencing and species delimitation

To test if multiple species of the same genera were present and to provide reference sequences for future studies, we sequenced a fragment of the Cytochrome C Oxidase subunit I (COI) barcode gene. Detailed methods of DNA sequencing and species delimitation, as well as the resulting GenBank accession numbers and species delimitation results are provided in SM.04.

\section{Results}

In total, 14 tardigrade genera were found in the analysed samples, with densities from 0 to 889 tardigrades per gram of dry substrate (SM.01). Tardigrades were found in $78.6 \%$ of the samples $(44 / 56)$. In three genera, multiple species were present, as revealed by COI barcoding (2 Ramazzottius spp., 2 Macrobiotus spp. and 2 Milnesium spp.; SM.04). The most common taxon, Ramazzottius, was found in $37.5 \%(21 / 56)$ of all examined rock pools with densities up to 860 individuals per gram of dry substrate (see SM.01). Mites and nematodes were absent or rare in most of the pools, whereas rotifers were always present and generally common (SM.01).

Prevalence was significantly higher in Pans than in Intermediates and Holes (Fig. 3a, Table 1), but no difference between Intermediates and Holes was detected. In addition, no significant difference in tardigrade density was found across pool types (Fig. 3b, Table 1), and pool area had no effect on either prevalence or density (Fig. 3c, Table 1). Although diversity was much higher in Pans than in Intermediates and Holes (although $P$ values are slightly above 0.05 , the effect size was very large; Fig. 3d, Table 1), no difference in diversity was found between Intermediates and Holes (Fig. 3d, Table 1). Neither sampling effort (how many individuals were classified) nor pool area had a significant effect on diversity (Fig. 3e, Table 1). We found significant differences in the trophic structure across rock pool types: the proportion of noncarnivorous tardigrades was significantly higher in Holes than in Pans and Intermediates, but no difference was found between the latter two types (Fig. 3f, Table 1). Finally, the proportion of non-carnivorous tardigrades was positively associated with density and pool area, but not significantly affected by rotifer abundance (Fig. 3g, Table 1).

\section{Discussion}

Prevalence, abundance and diversity

We show that tardigrades are abundant members of rock pool communities. In particular, we found prevalence and generic diversity are highest in the shallowest and thus driest pool category (Pans), when compared to the other two rock pool types (Intermediate and Holes). Interestingly, the tardigrade density was not significantly affected by pool type. This result contrasts with a previous study by Jocqué et al. (2007), which reported that high densities of tardigrades, rotifers and mites characterize shallower pools with short wet phases. Similar results (lower tardigrades density) were also obtained by Jönsson (2007) in mosses with experimentally increased hydration.

It is interesting to note that the tardigrade community composition at the generic level matches the one previously recorded in the same region (Bertolani \& Rebecchi, 1988-1996; Guidetti \& Bertolani, 2001) for mosses and lichens (Echiniscus, Macrobiotus, Milnesium, Minibiotus, and Ramazzottius) and for freshwater habitats (Grevenius, Mixibius). Whereas genera more typical of leaf litter (Guidetti \& Bertolani 2001; Hypsibius, Mesobiotus, Paramacrobiotus) 

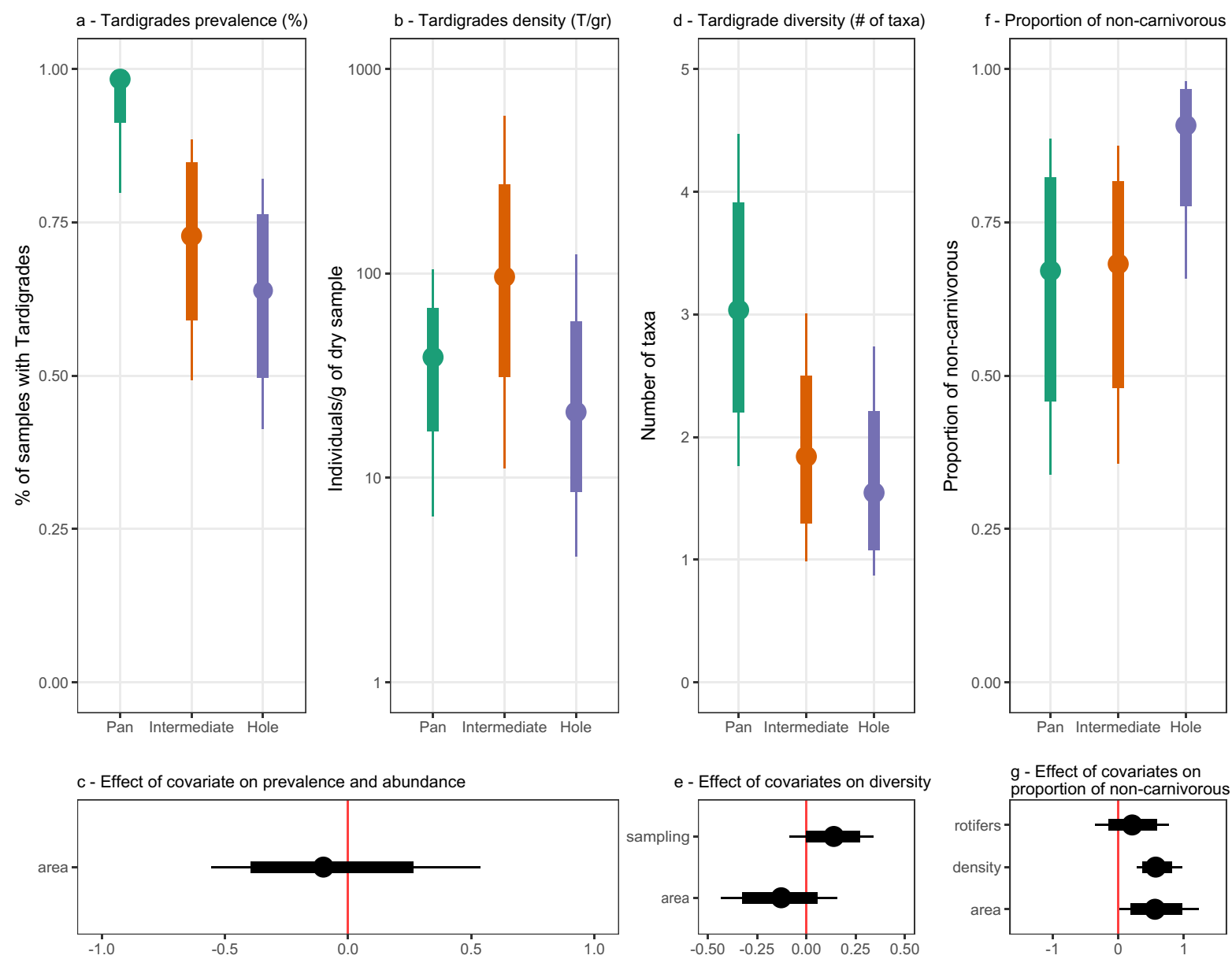

Fig. 3 Distribution of posterior estimates from BGLMM. a Tardigrade prevalence (percentage of samples with tardigrades); b Tardigrade density (number of individuals per gram of dry sample); c Effect of covariate (pool area) on tardigrade prevalence and abundance; $\mathbf{d}$ Tardigrade diversity (number of taxa); e Effect of covariates (sampling effort and pool area) on tardigrade diversity; f Proportion of non-carnivorous tardigrade individuals; $\mathbf{g}$ Effect of covariates (rotifer abundance, tardigrade density and pool area) on the proportion of non-carnivorous tardigrade individuals. Median (filled circle) with $80 \%$ (thick line) and $95 \%$ (thin line) Credible Intervals. ".” $P$ value $<0.1$, “*” $P$ value $<0.05$, “**” $P$ value $<0.01$

were absent or extremely rare. However, this comparison is only based on a classification to genus level. Therefore, it is not possible to exclude or confirm that the species found in the rock pools are the same as those recorded in the other types of habitat, nor if mosses and lichens are the source of the taxa present in rock pools.

The negative relationship between tardigrade taxonomic richness and water permanence is opposite to that reported in many other animal groups. Many studies from across the world have found a positive correlation between taxonomic richness in rock pools and water permanence (measured either as reduced desiccation frequency or as longer inundation periods) (King et al., 1996; Spencer et al., 1999; Therriault \& Kolasa, 2001; Eitam et al., 2004a; Vanschoenwinkel et al., 2009; Kulkarni et al., 2019). However, in one case, no relationship was found (Eitam et al., 2004b). Longer hydroperiods can allow species with slower developmental rates to thrive and benefit from temporal resource partitioning, thus favouring an increase in taxonomic richness (King et al., 1996). Those studies, however, mostly focused on larger microinvertebrates (crustaceans and flatworms), macroinvertebrates (insects) and vertebrates (amphibians); meiofaunal taxa such as tardigrades, rotifers, 
Table 1 Indices of existence and significance of the comparisons between the three different pool types and of the covariates
Calculation of standard effect size of effect of Area on Prevalence was not possible due to the model structure; “.” $P$ value $<0.1$, “*” $P$ value $<0.05$, “**” $P$ value $<0.01$

\begin{tabular}{|c|c|c|}
\hline & Bayesian $P$ value & Std. effect size (e.s.) \\
\hline \multicolumn{3}{|l|}{ Prevalence } \\
\hline Pan vs. Intermediate & $0.0193 *$ & 0.7992 \\
\hline Pan vs. Hole & $0.0073 * *$ & 1.0061 \\
\hline Intermediate $v s$. Hole & 0.5187 & 0.1959 \\
\hline \multicolumn{3}{|l|}{ Abundance } \\
\hline Pan vs. Intermediate & 0.1527 & -0.2424 \\
\hline Pan vs. Hole & 0.5107 & 0.3470 \\
\hline Intermediate $v s$. Hole & 0.1647 & 0.3097 \\
\hline Area & 0.6960 & -0.0006 \\
\hline \multicolumn{3}{|l|}{ Diversity } \\
\hline Pan vs. Intermediate & 0.0560 & 1.7560 \\
\hline Pan $v s$. Hole & 0.0627 & 2.1730 \\
\hline Intermediate $v s$. Hole & 0.6527 & 0.4981 \\
\hline Area & 0.3820 & -0.0983 \\
\hline Sampling & 0.2093 & 0.1075 \\
\hline \multicolumn{3}{|c|}{ Non-carnivorous proportion } \\
\hline Pan vs. Intermediate & 0.5187 & -0.0063 \\
\hline Pan vs. Hole & $0.0073 * *$ & -0.6317 \\
\hline Intermediate $v s$. Hole & $0.0193^{*}$ & -0.4131 \\
\hline Area & $0.0487 *$ & 0.3086 \\
\hline Density & $<0.0001 * *$ & 0.3148 \\
\hline Rotifers & 0.4387 & 0.1173 \\
\hline
\end{tabular}

and nematodes were rarely considered or classified below Phylum level.

A possible explanation for the higher tardigrade prevalence and diversity in Pans is perhaps the inability of predators to survive the frequent desiccation events. Larger predatory animals that could prey on tardigrades (for example, flatworms and insects that are known predators in rock pools; Brendonck et al., 2002) can resist desiccation only as eggs (Cáceres, 1997; Watanabe, 2006) and might not be able to complete their life cycle and produce new resistant eggs during the short inundation periods. In contrast, tardigrades are not constrained to completing their life cycle between desiccation events, as they can undergo anhydrobiosis in all life stages (Kaczmarek et al., 2019). This positive effect of frequent desiccation through lower predation pressure could explain the observed pattern in tardigrade prevalence and diversity, as already observed in other habitats (Herrmann et al., 2012). It is important to note that evidence of predation on tardigrades by other animals is very scarce. However, according to Schmid-Araya \& Schmid (2000), chironomids (Diptera: Chironomidae) from six out of the 17 genera for which data is available are known to feed on tardigrades. Chironomids have been commonly reported from freshwater rock pools (Brendonck et al., 2016), despite being unable to undergo anhydrobiosis (except Polypedilum vanderplanki Hinton, 1951 found only in the African continent; Cornette \& Kikawada, 2011). Thus, it is realistic to hypothesize that predation pressure on tardigrades from chironomids is reduced in rock pools that desiccate very fast. To test the latter, one would need to develop a sampling protocol tailored to consistently and quantitatively extract not only tardigrades but also chironomids (and flatworms). Nevertheless, we have qualitative data (see SM.01) that chironomids (pool E9) and flatworms (Gieysztoria sp. aequales group; frozen sample of pool E19) are present in the studied system. Also, one Gieysztoria individual was found with the traces of four tardigrades in its gut (SM.05), providing the first documented case of predation on tardigrades by a flatworm. 
Trophic structure

The tardigrade trophic groups were extremely biased toward non-carnivorous species in Holes. This reduction in carnivorous tardigrades is probably due to competition with other co-occurring invertebrate predators (chironomids and flatworms). Moreover, since predatory tardigrades (e.g., Paramacrobiotus and Milnesium) are usually larger than the herbivorous ones (e.g., Hypsibius and Grevenius) (Kosztyła et al., 2016; Roszkowska et al., 2016; Bryndová et al., 2020), they could also be more appealing prey for even larger predators (i.e., size-dependent predation, see for example Sprules, 1972 and Hohberg \& Traunspurger 2005). Both competition with, and preferential predation by, bigger predators could contribute to this extremely biased trophic structure in Holes compared to Pans and Intermediates. However, more studies are required to confirm this hypothesis. Trophic structure was also influenced by tardigrade density and pool area. Increasing tardigrade density is associated with a smaller proportion of carnivorous taxa, i.e., increases in tardigrade abundance are mostly due to the higher numbers of non-carnivorous taxa. Pool surface area, on the other hand, is associated with higher proportions of non-carnivorous tardigrades. It is possible that the larger surface area allows more solar radiation to be captured by algae and thus increases primary productivity, which would in turn support the growth and reproduction of algivorous taxa. Lastly, as rotifers are preyed on by carnivorous tardigrades (Roszkowska et al., 2016; Bryndová et al., 2020), it would be logical to predict a link between the two trophic level groups. In contrast, we found that rotifer abundance did not have a significant effect on the proportion of non-carnivorous tardigrades, which suggests that this type of prey availability is not a main factor influencing tardigrade community trophic structures.

\section{Other meiofauna}

Rotifers were both very common and abundant, whereas mites and nematodes were rare (SM.01). The identified mites belong to two species (Camisia invenusta (Michael, 1888) and Provertex kuehnelti Mihelčič, 1959) that are associated with mosses and lichens (Colloff, 1993; Hein et al., 2013). Therefore, they could have been transported by rain or wind from their habitats to the rock pools, where their presence represents accidental occurrences. Although nematodes are a dominant component of the soil community, and by far are the most abundant animals on Earth (Bardgett \& Van Der Putten, 2014), and usually co-occur with rotifers (Sohlenius, 1979; Sohlenius et al., 1996-2004), they do not seem to thrive in the studied rock pools. Interestingly, Zawierucha et al. (2021) also reported a scarcity of nematodes in cryoconites holes. Like tardigrades and rotifers, some nematodes species are able to undergo anhydrobiosis and survive extreme environmental stressors (Crowe \& Madin, 1974; McSorley, 2003) and thus it is not likely that the periodic desiccation events are the reason for their scarcity in the studied rock pools.

\section{Conclusions}

We found that thriving populations of tardigrades inhabit rock pools with community-level differences across different types of these habitats. This supports the idea that rock pools are a useful model system for the study of the ecological factors influencing tardigrade communities. Several fruitful new avenues of study are therefore possible. The small size of these habitats makes them amenable to experimental manipulation, or even in situ creation of new pools (see for example Evans et al., 2016; Sommers et al., 2019). In addition, their relative simplicity makes the application of metabarcoding (Arakawa, 2020; Topstad et al., 2021) possible, which would provide a complete and unbiased inventory of the meiofauna hosted in this unique and understudied ecosystem.

Acknowledgements We wish to acknowledge Dr. Tobias Pfingstl (Institute of Biology, University of Graz) for identifying the mites from pools D1 and E2, Chloe Fouilloux (Department of Biological and Environmental Sciences, University of Jyväskylä) for English improvements, Diego Fontaneto (CNR-IRSA Verbania Pallanza) for critical reading of our manuscript. Lastly, we wish to acknowledge Francesco Lami and Tommaso Sandri for assisting MV and CF during the third sampling trip. Samples were collected under sampling permits Prot.1128/2019 and Prot.1972/2020 issued to M.V. by Parco Nazionale Appennino Tosco-Emiliano (Massa-Carrara, Italy). The study was supported by an Academy of Finland Fellowship to S.C. (\#314219) and by the Preludium programme of the Polish National Science Centre (grant no. 2018/31/N/NZ8/03096 to DS). During this study, DS was supported by the Foundation for Polish Science (FNP). 
Author contributions MV conceptualised and designed the work, collected and analysed the samples, performed the statistical analysis, prepared figures, interpreted results and drafted the work. CF conceptualised the work, collected samples and interpreted results. DS produced molecular data and interpreted results. SC conceptualised the work, advised on the statistical analysis, interpreted results and drafted the work.

Funding Open Access funding provided by University of Jyväskylä (JYU). The study was supported by the Academy of Finland (Fellowship \#314219 to SC) and by the Preludium programme of the Polish National Science Centre (Grant No. 2018/31/N/NZ8/03096 to DS).

Data availability All data generated or analysed during this study are included in this published article, its supplementary information files and are openly available on Figshare (https:// doi.org/10.6084/m9.figshare.14482920). DNA sequences are deposited in GenBank at https://www.ncbi.nlm.nih.gov/genba $\mathrm{nk} /$ (Accession numbers in SM.04).

Code availability All code generated or analysed during this study is included in this published article, its supplementary information files and is openly available on Figshare (https:// doi.org/10.6084/m9.figshare.14482920).

\section{Declarations}

Conflict of interest The authors have no conflicts of interest to declare that are relevant to the content of this article.

Ethics approval Not applicable.

Consent to participate Not applicable.

Consent for publication Not applicable.

Open Access This article is licensed under a Creative Commons Attribution 4.0 International License, which permits use, sharing, adaptation, distribution and reproduction in any medium or format, as long as you give appropriate credit to the original author(s) and the source, provide a link to the Creative Commons licence, and indicate if changes were made. The images or other third party material in this article are included in the article's Creative Commons licence, unless indicated otherwise in a credit line to the material. If material is not included in the article's Creative Commons licence and your intended use is not permitted by statutory regulation or exceeds the permitted use, you will need to obtain permission directly from the copyright holder. To view a copy of this licence, visit http://creativecommons.org/licenses/by/4.0/.

\section{References}

Anusa, A., H. G. T. Ndagurwa \& C. H. D. Magadza, 2012. The influence of pool size on species diversity and water chemistry in temporary rock pools on Domboshawa
Mountain, northern Zimbabwe. African Journal of Aquatic Science 37: 89-99.

Arakawa, K., 2020. Simultaneous metabarcoding of eukaryotes and prokaryotes to elucidate the community structures within tardigrade microhabitats. Diversity 12: 110.

Bardgett, R. D. \& W. H. Van Der Putten, 2014. Belowground biodiversity and ecosystem functioning. Nature 515: 505-511.

Bartels, P. J. \& D. R. Nelson, 2006. A large-scale, multihabitat inventory of the Phylum Tardigrada in the Great Smoky Mountains National Park, USA: a preliminary report. Hydrobiologia 558: 111-118.

Bertolani, R. \& L. Rebecchi, 1988. The tardigrades of Emilia (Italy). I. Rossena. Italian Journal of Zoology 55: 367-371.

Bertolani, R. \& L. Rebecchi, 1996. The tardigrades of Emilia (Italy). II. Monte Rondinaio. A multihabitat study on a high altitude valley of the northern Apennines. Zoological Journal of the Linnean Society 116: 3-12.

Bertolani, R., R. Guidetti, T. Marchioro, T. Altiero, L. Rebecchi \& M. Cesari, 2014. Phylogeny of Eutardigrada: new molecular data and their morphological support lead to the identification of new evolutionary lineages. Molecular Phylogenetics and Evolution 76: 110-126.

Biserov, V.I., 1997-98. Tardigrades of the Caucasus with the taxonomic analysis of the genus Ramazzottius (Parachela: Hybsibiidea). Zoologischer Anzeiger 236: 139-159.

Boix, D., J. Kneitel, B. J. Robson, C. Duchet, L. Zúñiga, J. Day, S. Gascon, J. Sala, X. D. Quintana \& L. Blaustein, 2016. Invertebrates of freshwater temporary ponds in Mediterranean climates. In Batzer, D. \& D. Boix (eds), Invertebrates in Freshwater Wetlands Springer, Berlin: 141-189.

Brendonck, L., M. L. Hamer, B. J. Riddoch \& M. T. Seaman, 2000. Branchipodopsis species - specialists of ephemeral rock pools. Southern African Journal of Aquatic Sciences 25: 98-104.

Brendonck, L., E. Michels, L. De Meester \& B. Riddoch, 2002. Temporary pools are not 'enemy-free'. Hydrobiologia 486: $147-159$.

Brendonck, L., M. Jocqué, A. Hulsmans \& B. Vanschoenwinkel, 2010. Pools "on the rocks": freshwater rock pools as model system in ecological and evolutionary research. Limnetica 29: 25-40.

Brendonck, L., S. Lanfranco, B. Timms \& B. Vanschoenwinkel, 2016. Invertebrates in rock pools. In Batzer, D. \& D. Boix (eds), Invertebrates in Freshwater Wetlands Springer, Berlin: 25-53.

Bryndová, M., D. Stec, R. O. Schill, Ł Michalczyk \& M. Devetter, 2020. Dietary preferences and diet effects on life-history traits of tardigrades. Zoological Journal of the Linnean Society 188: 865-877.

Cáceres, C. E., 1997. Dormancy in invertebrates. Invertebrate Biology 116: 371-383.

Claxton, S. K., 1998. A revision of the genus Minibiotus (Tardigrada: Macrobiotidae) with descriptions of eleven new species from Australia. Records of the Australian Museum 50: 125-160.

Cohen, J., 1988. Statistical Power Analysis for the Social Sciences, Academic Publishers, New York:, 400. 
Colloff, M. J., 1993. A taxonomic revision of the oribatid mite genus Camisia (Acari: Oribatida). Journal of Natural History 27: 1325-1408.

Cornette, R. \& T. Kikawada, 2011. The induction of anhydrobiosis in the sleeping chironomid: status of our knowledge. IUBMB Life 63: 419-429.

Crowe, J. H. \& K. A. Madin, 1974. Anhydrobiosis in tardigrades and nematodes. Transactions of the American Microscopical Society 93: 513-524.

De Vries, C. H., 1996. Invertebrate community structure and dynamics in Korannaberg rock pools. MsC Thesis. University of the Orange Free State, Bloemfontein, South Africa.

Degma, P., R. Bertolani \& R. Guidetti, 2021. Actual checklist of Tardigrada species. https://doi.org/10.25431/11380_ 1178608. Accessed 10th Aug 2021.

Degma, P. \& R. Guidetti, 2007. Notes to the current checklist of Tardigrada. Zootaxa 1579: 41-53.

Deng, C., T. Daley \& A. Smith, 2015. Applications of species accumulation curves in large-scale biological data analysis. Quantitative Biology 3: 135-144.

Eitam, A., L. Blaustein, K. Van Damme, H. J. Dumont \& K. Martens, 2004a. Crustacean species richness in temporary pools: relationships with habitat traits. Hydrobiologia 525: 125-130.

Eitam, A., C. Noreña \& L. Blaustein, 2004b. Microturbellarian species richness and community similarity among temporary pools: relationships with habitat properties. Biodiversity \& Conservation 13: 2107-2117.

Evans, A. J., L. B. Firth, S. J. Hawkins, E. S. Morris, H. Goudge \& P. J. Moore, 2016. Drill-cored rock pools: an effective method of ecological enhancement on artificial structures. Marine and Freshwater Research 67: 123-130.

Ferrari, C. \& F. Piccoli, 1997. The ericaceous dwarf shrublands above the Northern Apennine timberline (Italy). Phytocoenologia 28: 53-76.

Foggi, B. \& G. Rossi, 1996. A survey of the genus Festuca L. (Poaceae) in Italy. I. The species of the summit flora in the Tuscan-Emilian Apennines and Apuan Alps. Willdenowia 26: 183-215.

Fontaneto, D., 2019. Long-distance passive dispersal in microscopic aquatic animals. Movement Ecology 7: 10.

Gansfort, B., W. Traunspurger, I. Threis \& N. Majdi, 2018. Wide variation in a tiny space: the microdistribution of meiobenthos in an artificial pond. Freshwater Biology 63: 420-431.

Gąsiorek, P. \& Ł Michalczyk, 2020. Phylogeny of Itaquasconinae in the light of the evolution of the flexible pharyngeal tube in Tardigrada. Zoologica Scripta 49: 499-515.

Gąsiorek, P., W. Morek, D. Stec \& Ł Michalczyk, 2019a. Untangling the Echiniscus Gordian knot: paraphyly of the "arctomys group" (Heterotardigrada: Echiniscidae). Cladistics 35: 633-653.

Gąsiorek, P., D. Stec, W. Morek \& Ł Michalczyk, 2019b. Deceptive conservatism of claws: distinct phyletic lineages concealed within Isohypsibioidea (Eutardigrada) revealed by molecular and morphological evidence. Contributions to Zoology 88: 78-132.
Guidetti, R. \& R. Bertolani, 2001. The tardigrades of Emilia (Italy). III. Piane di Mocogno (Northern Apennines). Zoologischer Anzeiger 240: 377-383.

Guidetti, R. \& R. Bertolani, 2005. Tardigrade taxonomy: an updated checklist of the taxa and a list of characters for their identification. Zootaxa 845: 1-46.

Guidetti, R., T. Altiero \& L. Rebecchi, 2011. On dormancy strategies in tardigrades. Journal of Insect Physiology 57: 567-576.

Hansen, J. G., R. M. Kristensen, R. Bertolani \& R. Guidetti, 2017. Comparative analyses of Bertolanius species (Eohypsibiidae; Eutardigrada) with the description of Bertolanius birnae sp. nov. from northern polar regions. Polar Biology 40: 123-140.

Hein, N., T. Solhøy, H. Schatz \& J. Löffler, 2013. An orbatid species Provertex kuehnelti Mihelčič, 1959 (Acari, Orbatida) new to Fennoscandia. Norwegian Journal of Entomology 60: 163-1680.

Herrmann, J., U. Kormann, C. Schüepp, Y. Stocker, F. Herzog \& M. Entling, 2012. Effects of habitat isolation and predation pressure on an arboreal food-web. Community Ecology 13: 82-87.

Hohberg, K. \& W. Traunspurger, 2005. Predator-prey interaction in soil food web: functional response, size-dependent foraging efficiency, and the influence of soil texture. Biology and Fertility of Soils 41: 419-427.

Jeffries, M., 1994. Invertebrate communities and turnover in wetland ponds affected by drought. Freshwater Biology 32: 603-612.

Jocqué, M., K. Martens, B. Riddoch \& L. Brendonck, 2006. Faunistics of ephemeral rock pools in southeastern Botswana. Archiv Für Hydrobiologie 165: 415-431.

Jocqué, M., T. Graham \& L. Brendonck, 2007. Local structuring factors of invertebrate communities in ephemeral freshwater rock pools and the influence of more permanent water bodies in the region. Hydrobiologia 592: 271-280.

Jocqué, M., B. Vanschoenwinkel \& L. Brendonck, 2010. Freshwater rock pools: a review of habitat characteristics, faunal diversity and conservation value. Freshwater Biology 55: $1587-1602$.

Jönsson, K. I., 2007. Long-term experimental manipulation of moisture conditions and its impact on moss-living tardigrades. Journal of Limnology 66: 119-125.

Kaczmarek, Ł, M. Roszkowska, D. Fontaneto, M. Jezierska, B. Pietrzak, R. Wieczorek, I. Poprawa, J. Z. Kosicki, A. Karachitos \& H. Kmita, 2019. Staying young and fit? Ontogenetic and phylogenetic consequences of animal anhydrobiosis. Journal of Zoology 309: 1-11.

Kathman, R. D. \& D. R. Nelson, 1987. Population trends in the aquatic tardigrade Pseudobiotus augusti (Murray). In Bertolani, R. \& M. Balsamo (eds), Biology of Tardigrades. Selected Symposia and Monographs UZI Mucchi Editore, Modena: 155-168.

Kinchin, I. M., 1989. Hypsibius anomalus Ramazzotti (Tardigrada) from gutter sediment. Microscopy 36: 240-244.

Kinchin, I. M., 1996. Morphometric analysis of Ramazzottius varieornatus (Hypsibiidae: Eutardigrada). Zoological Journal of the Linnean Society 116: 51-60.

King, J. L., M. A. Simovich \& R. C. Brusca, 1996. Species richness, endemism and ecology of crustacean 
assemblages in northern California vernal pools. Hydrobiologia 328: 85-116.

Koste, W., 1996. On soil Rotatoria from a lithotelma near Halali Lodge in Etosha National Park in N-Namibia, South Africa. Internationale Revue Der Gesamten Hydrobiologie Und Hydrographie 81: 353-365.

Kosztyła, P., D. Stec, W. Morek, P. Gąsiorek, K. Zawierucha, K. Michno, K. Ufir, D. Małek, K. Hlebowicz, A. Laska, M. Dudziak, M. Frohme, Z. M. Prokop, Ł Kaczmarek \& Ł Michalczyk, 2016. Experimental taxonomy confirms the environmental stability of morphometric traits in a taxonomically challenging group of microinvertebrates. Zoological Journal of the Linnean Society 178: 765-775.

Kulkarni, M. R., S. M. Padhye, R. B. Rathod, Y. S. Shinde \& K. Pai, 2019. Hydroperiod and species-sorting influence metacommunity composition of crustaceans in temporary rock pools in India. Inland Waters 9: 320-333.

Makowski, D., M. S. Ben-Shachar, S. H. Chen \& D. Lüdecke, 2019a. Indices of effect existence and significance in the Bayesian framework. Frontiers in Psychology 10: 2767.

Makowski, D., M. S. Ben-Shachar \& D. Lüdecke, 2019b. bayestestR: describing effects and their uncertainty, existence and significance within the Bayesian framework. Journal of Open Source Software 4: 1541.

Marcus, V. \& S. C. Weeks, 1997. The effects of pond duration on the life history traits of an ephemeral pond crustacean, Eulimnadia texana. In Simovich, M. A., C. Sassaman \& D. Belk (eds), Studies on Large Branchiopod Biology and Conservation Springer, Berlin: 213-221.

Mariani, G. S., M. Cremaschi, A. Zerboni, L. Zuccoli \& L. Trombino, 2018. Geomorphology of the Mt. Cusna ridge (northern Apennines, Italy): evolution of a Holocene landscape. Journal of Maps 14: 392-401.

McElreath, R., 2018. Statistical Rethinking: A Bayesian Course with Examples in $\mathrm{R}$ and Stan, Chapman and Hall/CRC, Boca Raton:

McSorley, R., 2003. Adaptations of nematodes to environmental extremes. Florida Entomologist 86: 138-142.

Møbjerg, N., A. Jørgensen, R. M. Kristensen \& R. C. Neves, 2018. Morphology and functional anatomy. In Schill, R. O. (ed), Water Bears: The Biology of Tardigrades Springer, Berlin: 57-94.

Morek, W., P. Gąsiorek, D. Stec, B. Blagden \& Ł Michalczyk, 2016a. Experimental taxonomy exposes ontogenetic variability and elucidates the taxonomic value of claw configuration in Milnesium Doyère, 1840 (Tardigrada: Eutardigrada: Apochela). Contributions to Zoology 85: 173-200.

Morek, W., D. Stec, P. Gąsiorek, R. O. Schill, Ł Kaczmarek $\& \succeq$ Michalczyk, 2016b. An experimental test of eutardigrade preparation methods for light microscopy. Zoological Journal of the Linnean Society 178: 785-793.

Neher, D. A., S. A. Lewins, T. R. Weicht \& B. J. Darby, 2009. Microarthropod communities associated with biological soil crusts in the Colorado Plateau and Chihuahuan deserts. Journal of Arid Environments 73: 672-677.

Nelson, D. R., P. J. Bartels \& N. Guil, 2018. Tardigrade ecology. In Schill, R. O. (ed), Water Bears: The Biology of Tardigrades Springer, Berlin: 163-210.
Oksanen, J., F. G. Blanchet, M. Friendly, R. Kindt, P. Legendre, D. McGlinn, R. Minchin, R. B. O’Hara, G. L. Simpson, P. Solymos, M. H. H. Stevens, E. Szoecs \& H. Wagner, 2020. Package 'vegan'. Community Ecology Package, p. 298.

Pedersen, T. L., 2020. patchwork: The Composer of Plots. p. 18. https://github.com/thomasp85/patchwork.

Pignatti, S., 1994. The climax vegetation above timberline in the northern and central Apennines. Fitosociologia 26: 5-17.

Pilato, G., 1992. Mixibius, nuovo genere di Hypsibiidae (Eutardigrada). Animalia 19: 121-125.

Plummer, M., 2003. JAGS: A program for analysis of Bayesian graphical models using Gibbs sampling. In K. Hornik, F. Leisch \& A. Zeileis. Achim Zeileis (eds) Proceedings of the 3rd International Workshop on Distributed Statistical Computing.

Ptatscheck, C., B. Gansfort \& W. Traunspurger, 2018. The extent of wind-mediated dispersal of small metazoans, focusing nematodes. Scientific Reports 8: 1-10.

R Core Team, 2020. R: A language and environment for statistical computing. R Foundation for Statistical Computing, Vienna.

Ramazzotti, G., \& Maucci, W., 1983. Il Phylum Tardigrada, (CW Beasley, English Translation). Memorie dell' Istituto Idrobiologia. Istituto Italiano di Idrobiologia, p. 1014.

Roszkowska, M., P. J. Bartels, B. Gołdyn, D. A. Ciobanu, P. Fontoura, Ł Michalczyk, D. R. Nelson, M. Ostrowska, A. Moreno-Talamantes \& $€$ Kaczmarek, 2016. Is the gut content of Milnesium (Eutardigrada) related to buccal tube size? Zoological Journal of the Linnean Society 178: 794-803.

Schmid-Araya, J. M. \& P. E. Schmid, 2000. Trophic relationships: integrating meiofauna into a realistic benthic food web. Freshwater Biology 44: 149-163.

Schuster, R. \& H. Greven, 2007. A long-term study of population dynamics of tardigrades in the moss Rhytidiadelphus squarrosus (Hedw.) Warnst. Journal of Limnology 66: 141-151.

Schuster, R. O., E. C. Toftner \& A. A. Grigarick, 1977. Tardigrada of Pope Beach. Lake Tahoe, California. Wusmann. Journal of Biology 35: 115-136.

Snoeks, J. M., M. Driesen, S. Porembski, Á. Aristizábal-Botero \& B. Vanschoenwinkel, 2021. Contrasting biodiversity and food web structure of three temporary freshwater habitats in a tropical biodiversity hotspot. Aquatic Conservation: Marine and Freshwater Ecosystems. https:// doi.org/10.1002/aqc.3670.

Sohlenius, B., 1979. A carbon budget for nematodes, rotifers and tardigrades in a Swedish coniferous forest soil. Ecography 2 : $30-40$.

Sohlenius, B., S. Boström \& A. Hirschfelder, 1996. Distribution patterns of microfauna (nematodes, rotifers and tardigrades) on nunataks in Dronning Maud Land, East Antarctica. Polar Biology 16: 191-200.

Sohlenius, B., S. Boström \& K. I. Jönsson, 2004. Occurrence of nematodes, tardigrades and rotifers on ice-free areas in East Antarctica. Pedobiologia 48: 395-408.

Sommers, P., D. L. Porazinska, J. L. Darcy, F. Zamora, A. G. Fountain \& S. K. Schmidt, 2019. Experimental 
cryoconite holes as mesocosms for studying community ecology. Polar Biology 42: 1973-1984.

Spencer, M., L. Blaustein, S. S. Schwartz \& J. E. Cohen, 1999. Species richness and the proportion of predatory animal species in temporary freshwater pools: relationships with habitat size and permanence. Ecology Letters 2: 157-166.

Sprules, W. G., 1972. Effects of size-selective predation and food competition on high altitude zooplankton communities. Ecology 53: 375-386.

Srivastava, D. S., J. Kolasa, J. Bengtsson, A. Gonzalez, S. P. Lawler, T. E. Miller, P. Munguia, T. Romanuk, D. C. Schneider \& M. K. Trzcinski, 2004. Are natural microcosms useful model systems for ecology? Trends in Ecology \& Evolution 19: 379-384.

Stec, D., W. Morek, P. Gąsiorek \& Ł Michalczyk, 2018. Unmasking hidden species diversity within the Ramazzottius oberhaeuseri complex, with an integrative redescription of the nominal species for the family Ramazzottiidae (Tardigrada: Eutardigrada: Parachela). Systematics and Biodiversity 16: 357-376.

Stec, D., M. Vecchi, S. Calhim \& Ł Michalczyk, 2021. New multilocus phylogeny reorganises the family Macrobiotidae (Eutardigrada) and unveils complex morphological evolution of the Macrobiotus hufelandi group. Molecular Phylogenetics and Evolution 160: 106987.

Su, Y. S. \& Yajima, M., 2015. R2jags: Using R to Run 'JAGS'. $\mathrm{R}$ package version $0.5-7$.

Tevis, J. L., 1966. Unsuccessful breeding by desert toads (Bufo punctatus) at the limit of their ecological tolerance. Ecology 47: 766-775.

Therriault, T. W. \& J. Kolasa, 2001. Desiccation frequency reduces species diversity and predictability of community structure in coastal rock pools. Israel Journal of Zoology 47: 477-489.

Tomaselli, M., B. Foggi, M. Carbognani, M. Gennai \& A. Petraglia, 2019. The rock-face vegetation in the northern Apennines and neighbouring mountain areas, from the coast line to the highest summits. Phytocoenologia 49: 7-70.

Topstad, L., R. Guidetti, M. Majaneva \& T. Ekrem, 2021. Multi-marker DNA metabarcoding reflects tardigrade diversity in different habitats. Genome 64: 217-231.

Tumanov, D. V., 2020. Integrative redescription of Hypsibius pallidoides Pilato et al., 2011 (Eutardigrada: Hypsibioidea) with the erection of a new genus and discussion on the phylogeny of Hypsibiidae. European Journal of Taxonomy 681: 1-37.

Vanschoenwinkel, B., A. Hulsmans, E. De Roeck, C. De Vries, M. Seaman \& L. Brendonck, 2009. Community structure in temporary freshwater pools: disentangling the effects of habitat size and hydroregime. Freshwater Biology 54: 1487-1500.

Vecchi, M., M. Cesari, R. Bertolani, K. I. Jönsson, L. Rebecchi \& R. Guidetti, 2016. Integrative systematic studies on tardigrades from Antarctica identify new genera and new species within Macrobiotoidea and Echiniscoidea. Invertebrate Systematics 30: 303-322.

Velasco-González, I., A. Sanchez-Jimenez, D. Singer, A. Murciano, S. Díez-Hermano, E. Lara \& M. Martín-Cereceda, 2020. Rain-fed granite rock basins accumulate a high diversity of dormant microbial eukaryotes. Microbial Ecology 79: 882-897.

Watanabe, M., 2006. Anhydrobiosis in invertebrates. Applied Entomology and Zoology 41: 15-31.

Wickham, H., M. Averick, J. Bryan, W. Chang, L. D. A. McGowan, R. François, G. Grolemund, A. Hayes, L. Henry, J. Hester, M. Kuhn, T. L. Pedersen, E. Miller, S. M. Bache, K. Müller, J. Ooms, D. Robinson, S. M. Seidel, V. Spinu, K. Takahashi, D. Vaughan, C. Wilke, K. Woo \& H. Yutani, 2019. Welcome to the Tidyverse. Journal of Open Source Software 4: 1686.

Wright, J. C., 2001. Cryptobiosis 300 years on from van Leuwenhoek: what have we learned about tardigrades? Zoologischer Anzeiger 240: 563-582.

Zawierucha, K., M. Ostrowska, T. R. Vonnahme, M. Devetter, A. P. Nawrot, S. Lehmann \& M. Kolicka, 2016. Diversity and distribution of Tardigrada in Arctic cryoconite holes. Journal of Limnology 75: 545-559.

Zawierucha, K., K. Zmudczyńska-Skarbek, N. Guil \& M. Bogdziewicz, 2019. Seabirds modify trophic groups, while altitude promotes xeric-tolerant species of Tardigrada in the high Arctic tundra (Svalbard archipelago). Acta Oecologica 98: 50-58.

Zawierucha, K., D. L. Porazinska, G. F. Ficetola, R. Ambrosini, G. Baccolo, J. Buda, J. L. Ceballos, M. Devetter, R. Dial, A. Franzetti, U. Fuglewicz, L. Gielly, E. Łokas, K. Janko, T. N. Jaromerska, A. Koscinski, A. Kozłowska, M. Ono, I. Parnikoza, F. Pittino, E. Poniecka, P. Sommers, S. K. Schmidt, D. Shain, S. Sikorska, J. Uetake \& N. Takeuchi, 2021. A hole in the nematosphere: tardigrades and rotifers dominate the cryoconite hole environment, whereas nematodes are missing. Journal of Zoology $313: 18-36$.

Publisher's Note Springer Nature remains neutral with regard to jurisdictional claims in published maps and institutional affiliations. 